\title{
Safety, efficacy and compliance of extended thromboprophylaxis in Hepatobiliary and Upper Gastrointestinal Surgery.
}

Short title: Extended Venothromboprohylaxis in Hepatobiliary and Upper Gastrointestinal surgery

\section{Authors:}

Leah Marley MBBS ${ }^{1}$, Suresh Navadgi FRACS ${ }^{1}$, Simon Banting FRACS ${ }^{1,2}$, Adrian Fox FRACS ${ }^{1}$ ${ }^{2}$, Michael Hii FRACS ${ }^{1,2}$ and Brett Knowles FRACS ${ }^{1,2}$

${ }^{1 .}$ St Vincent's Hospital, Melbourne, Victoria, Australia, ${ }^{2}$ The University of Melbourne, Victoria, Australia

The corresponding author is not a recipient of a research scholarship

There is one table and two figures:

Table 1. Patient demographics

Figure 1. Number of missed injections per study participant

Figure 2. Complications reported by study participants

Abstract word count: 237

Text word count: 2495

Author contact details:

Dr Leah Marley

lkmarley@gmail.com

4/42-50 Napier Crescent Essendon, Victoria, Australia, 3040

Phone: 0414861666

This is the author manuscript accepted for publication and has undergone full peer review but has not been through the copyediting, typesetting, pagination and proofreading process, which may lead to differences between this version and the Version of Record. Please cite this article as doi: $10.1111 /$ ans.14287

This article is protected by copyright. All rights reserved. 


\title{
Safety, efficacy and compliance of extended thromboprophylaxis in Hepato-biliary and Upper Gastrointestinal Surgery.
}

\author{
Leah Marley MBBS ${ }^{1}$, Suresh Navadgi FRACS ${ }^{1}$, Simon Banting FRACS $^{1,2}$, Adrian Fox $_{\text {FRACS }}{ }^{1,2}$, \\ Michael Hii FRACS ${ }^{1,2}$ and Brett Knowles FRACS ${ }^{1,2}$ \\ 1. St Vincent's Hospital, Melbourne, Victoria, Australia, ${ }^{2}$ The University of Melbourne, Victoria, \\ Australia
}

Background: Extended venothomboprophylaxis (eVTP) after abdominal surgery for hepato-biliary (HPB) and upper gastrointestinal (UGI) malignancies is recommended. Safety, efficacy and compliance within this group of surgical patients is not well described.

$\operatorname{Aim}(s)$ : The primary aim was to assess safety and compliance of post-operative administration of eVTP with low molecular weight heparin (LMWH). Secondary aim was to assess barriers to treatment and monitor the rate of post-operative venothromboembolism (VTE)

Methods: A prospective observational cohort study of patients undergoing abdominal surgery for HPB or UGI malignancies was undertaken from January 2014 to June 2016. All patients were assessed for eVTP. Demographics, clinical outcomes and clinical questionnaires on discharge and at follow up 6 weeks post their initial surgery were used to assess the safety, compliance and efficacy of eVTP.

This article is protected by copyright. All rights reserved. 
Results: 100 patients were assessed for post-operative eVTP. Of these, 80 patients were prescribed 28 days of LMWH. 65 of 80 (85\%) patients completed the full eVTP. 11 patients (13\%) missed 1 to 5 injections and only 4 (6\%) 6 to 15 injections. In the 80 eVTP patients there were no episodes of significant bleeding or VTE. 9 patients (11\%) would be unwilling to undertake eVTP again for a variety of reasons, including ease of disposal of syringes and needle phobias

Conclusion: The administration of eVTP in patients undergoing major hepato-biliary and upper GI surgery is safe, with minimal morbidity and high compliance. The greatest barrier to administration is doctor prescription.

ABSTRACT WORD COUNT: 238 words

\section{TEXT WORD COUNT: 2450 words}

\section{INTRODUCTION}

Within the oncologic patient population, venous thromboembolism (VTE) is a significant source of mortality, morbidity and subsequent utilisation of health resources. The incidence of VTE in patients with any cancer is1-3\% and is increased further with surgery and/or chemotherapy ${ }^{1}$. Venothrombophylaxis is well documented as a safe and cost-effective measure to reduce the risk of VTE while a patient is in hospital ${ }^{2}$, however safety, efficacy and compliance of extended Venothromboprophylaxis (eVTP) post discharge is less well studied, particularly in patients undergoing surgery for hepato-biliary (HPB) and upper gastrointestinal (UGI) malignancies.

Two randomised controlled trials and a meta-analysis have shown that extended prophylaxis in surgical patients up to 4 weeks post operatively with low molecular weight heparin (LMWH) reduces the incidence of VTE by $60 \%$ compared with prophylaxis limited to the in-hospital stay

This article is protected by copyright. All rights reserved. 
without increasing the risk of bleeding ${ }^{3,4,5}$. On the basis of these results, National Health Service (NHS) National Institute for health and Care Excellence (NICE) ${ }^{6}$, American college of chest physicians $(\mathrm{CHEST})^{7}$ and the Australian National Health and Medical Research Council (NHMRC) recommend eVTE in cancer patients undergoing abdominal surgery ${ }^{8}$.

Within these trials there are only a few patients undergoing major HPB or UGI surgeries. Any benefit for eVTP must offset any increase in surgical complications and out of hospital LMWH administration must be practical and have good compliance. This study sought to assess safety and compliance of eVTP with LMWH in the HPB/UGI population. The secondary endpoints were to assess the incidence of VTE and bleeding, and finally to assess any barriers to treatment.

\section{METHODS}

Between May 2014 and May 2016 all patients undergoing major surgery for UGI/HPB malignancies were assessed for eligibility for eVTP. This consisted of 28 days of LMWH (Clexane Sanofi) at $0.5 \mathrm{mg}$ per Kg daily, started from the day of surgery. Due to restrictions placed on clexane quantities prescribed without authority as per the PBS, outpatient prescription was limited to twenty injections. On consultation with haematology, advice was that patients should receive a total 28 days or number of days in hospital plus 20 injections once discharged. Due to this, 21 patients who were discharged prior to day eight had a shorter course (range 24 to 27 days). Patients were excluded from the study protocol if they had a history of previous VTE, were already taking anticoagulation, pregnant or thrombocytopenic (Platelets $<50$ ). In addition, any patient who had an inpatient event requiring the commencement of long term therapeutic anticoagulation (VTE, acute myocardial infarction, atrial fibrillation etc.) were excluded.

This article is protected by copyright. All rights reserved. 
A two-part questionnaire was used. The first part was undertaken on discharge and assessed the participant's competency and understanding to deliver the LMWH. During the admission patients were educated to self-administer LMWH injection by a registered nurse, and in addition written and DVD instructions were supplied. Those patients not comfortable administering the injections themselves had either a relative trained in administration, were linked with the Royal District Nursing service (RDNS) or general practitioner (GP) to provide injections. All patients received outpatient support with written information, a sharps container for needle disposal and the contact details of the unit registrar. Since completion of this study, Sanofi Clexane have moved from DVD education to website based education ${ }^{9}$.

At six weeks post discharge the second part of the questionnaire was undertaken, either at a routine post-operative outpatient appointment, or via a phone call by the primary researcher. This assessed compliance, complications the patients experienced, including screening for clinical VTE, bleeding, rash or significant pain experienced at the injection site. The last part of the survey looked at the patient's experience during the study, with a rating from 1-5 (from extremely convenient to extremely inconvenient), and whether they would be willing to undertake eVTP again. The questionnaire also provided room for the participant to provide any comments/feedback to the researcher regarding their post-operative LMWH therapy. Both methods of reporting were completed with exclusive use of the follow-up questionnaire. In all cases the grading system was explained prior and the patient was given opportunity to express any thoughts or questions. The grading system was used for the quantitative portion of the results, and the comments were combined into major themes (e.g. comments on alternatives to needles etc.) 
All responses generated categorical data and were reported as frequencies with proportions. The study protocol was assessed and approved by the St Vincent's ethical committee.

\section{RESULTS}

There were 114 UGI/HPB major abdominal resections for malignancy between May 2014 and May 2016. Of these, 100 consecutive patients met inclusion criteria to be offered eVTP upon discharge. Twenty patients declined participation, and of the remaining 80 patients who were eligible, 65 (85\%) were prescribed eVTP. Of the $20 \%$ of patients who declined participation, reasons included significant needle phobia, patients who felt they were already taking too many medications and did not wish to add another, those who felt the injections would not be useful despite education, and several who felt that it would be too inconvenient due to distance from the local hospital/pharmacy/no support to provide injections (despite support being offered). The remaining $15 \%$ were not prescribed eVTP by the attending surgeons despite eligibility. Of the 65 participants, 28 patients (43\%) underwent major liver resections, 19 (29\%) major pancreatic resections, 8(12\%) Ivor Lewis Oesophagectomies, nine (14\%) partial/total gastrectomies and one (2\%) a radical extra hepatic biliary tree excision. Patient characteristics are reported in Table 1.

Of the 65 patients prescribed eVTP, 50 (77\%) had 100\% compliance. Of the 15 who missed injections, 11 (13\%) missed 1-5 injections, and four (6\%) missed 6-15 injections (Fig. 1). The majority, 45 patients (69\%), were able to administer their injections independently, while 20 patients (31\%) required an aide to assist. Patients who missed their injections gave reasons including simply forgetting (10 patients), finding the injections painful (three patients) or not wanting to complete the full course of the medication (two patients).

This article is protected by copyright. All rights reserved. 
At the time of discharge, 62 (96\%) of patients said they understood the reason for using LMWH and were happy to undertake outpatient eVTP, while three (4\%) patients stated they were not sure why they were receiving the injections. Two were patients from non-English speaking backgrounds, and upon discussion with an interpreter present, good compliance was achieved.

At the six week follow up $43(66 \%)$ patients reported no complications. 17 (26\%) patients reported bruising at the injection site, and four (6\%) patients reported pain at the injection site, three (4\%) commenting it was only mild pain, while one $(2 \%)$ reported significant pain which caused him to skip multiple injections. One (2\%) patient experienced puritis at the injection site (Fig 2).

Five (8\%) patients stated they had experienced either shortness of breath (SOB) or swollen legs in the postoperative period. Of these, one was noted to have oedema which was pre-existing, one had ascites causing his SOB, two were investigated by their GPs and deemed not to have VTE. The final patient stated he had chest pain on exertion, and underwent a cardiac workup with no VTE identified. Thus, no clinical episodes of VTE were diagnosed in eVTP treatment cohort. None of the 15 patients eligible but not prescribed eVTP had symptoms nor diagnosis of VTE at six weeks.

At the same six week follow up, patients were asked to rate from 1 - 5 (1 = extremely convenient, 5 = very inconvenient) the ease of administration of LMWH during their daily routine. 63 patients (97\%) stated it was very convenient, convenient or no bother. Many of these patients commented they took the injection at the same time as their other medication, or had an aid (nurse etc.) who helped administer it. 2 patients (3\%) rated administering the LMWH as $4=$ inconvenient. One commented he would have preferred tablets, and another on the difficulty remembering to take the injections as they had no one to remind them.

This article is protected by copyright. All rights reserved. 
Ease of disposal was also assessed with the same convenience score. 53 patients (81\%) stated the needles were easy to dispose of, mostly by returning them to the pharmacy or having the nurse assisting with administration dispose of them. 12 patients (19\%) scored a 3 or 4 for convenience. Two of these patients lived some distance from a pharmacy and felt disposing of the needles was difficult due to travel requirements, while another commented that the needles were still at home. One of these patients did complete the therapy despite this, and would be willing to undergo eVTP again. The other patient missed 2 injections however would not repeat eVTP if required in the future.

At the six week follow up patients were asked if they would undergo eVTP prophylaxis again. 56 patients $(86 \%)$ replied yes, while nine patients $(14 \%)$ stated they would not. Of these nine patients, three stated they did not like the injections due to the pain they caused, two stated they felt disposal of the needles was too difficult, one stated he would undertake eVTP again but only if tablets were available, one would do it again but only if a nurse was available, and two stated they forgot so frequently they felt it wasn't worth trying again.

Of the 65 patients who completed the study, none had significant episodes of bleeding.

\section{DISCUSSION}

In this prospective cohort of patients undergoing major HPB and UGI abdominal surgery administration of extended LMWH was safe. None of the patients on the study required readmission for complications of bleeding and there were no episodes of clinical VTE.

VTE pharmacoprophylaxis involves a tradeoff between preventing thrombosis and increased bleeding risk. Recent population based studies highlight a significant baseline risk for VTE in patients

This article is protected by copyright. All rights reserved. 
undergoing surgery ${ }^{10,11}$. In the HPB population the best estimate of this underlying risk comes from a review of the National Surgical Quality Improvement Program (NSQIP) database. The relationship between extent of hepatectomy, postoperative VTE and bleeding events was evaluated for 5651 hepatectomy patients from 2005 to 2009 . The overall postoperative VTE incidence was $2.88 \%$ (DVT $1.9 \%$, PE $1.3 \%$ ) with a postoperative transfusion rate of $0.76 \%$. VTE increased with the magnitude of hepatectomy (partial 2.13\%, left 2.05\%, right $4.15 \%$, extended $5.76 \% ; P<0.001$ ) and outnumbered bleeding events $(P<0.001)^{12}$.

In addition, studies have shown that patients who have VTE associated with cancer have a poorer prognosis than those with cancer alone ${ }^{13,14}$, and that VTE is one of the leading causes for death in this patient group ${ }^{13,15,16}$. Taken together surgical patients undergoing surgery appear to have double the risk of DVT and nearly three times the risk of fatal PE than surgical patients without cancer ${ }^{17}$. Further studies have highlighted that up to a third of VTE events occur in the outpatient setting ${ }^{18}$ and that an increased risk of VTE persists for up to 12 weeks post-surgery ${ }^{11}$. This led to three randomised controlled trials of inpatient LMWH versus eVTP in patients undergoing abdominal surgery for malignancy that have been analysed in two meta-analyses. These demonstrate a significant reduction in VTE (OR 0.22) without a significant increase in bleeding ${ }^{5,19,20}$. However, trial data comes largely from abdominal (colorectal cancer) and pelvic cancer with few patients undergoing major UGI, Liver, Pancreatic and Biliary surgeries included. Our compliance rate was excellent (77\%). This differs to reported compliance in the United States - Merkow et al found that only $1.2 \%$ patients aged 65 or older filled a prescription for LMWH post discharge after a major colorectal cancer resection ${ }^{21}$, while a study from Switzerland showed that only $25 \%$ of patients post major abdominal cancer surgery received a script for eVTP ${ }^{22,23}$. In these studies, financial barriers were considered the prime reason for poor compliance, which in our population is not an issue, due 
to patients receiving their prescriptions on discharge (supplied at no cost) and for most the out of hospital costs (nurses, trips to GP etc.) are covered by our health system.

Major bleeding post UGI/HPB surgery is associated with a significant morbidity and mortality

${ }^{24}$. Anecdotal evidence has worried about a higher risk of bleeding postoperatively with early and eVTP. Our experience mirrors others that the risk of bleeding is not significantly elevated and likely to be outweighed by the protective effect of LMWH against DVT/PE ${ }^{25,26,27}$.

This study looked at the patient experience, as well as compliance and efficacy of eVTP in the post-operative setting. Patients who agreed to participate in the study were given a full education program prior to discharge, and during this period any barriers to receiving the full course of LMWH were identified to ensure the patient had the best opportunity to complete the course post discharge. This included, but was not limited to, identifying patients who could not self-inject (providing these patients with an alternative provider of care), patients with large number of medications already (including it in their general routine) and ensuring understanding was clear in non-English speaking participants (providing interpreters).

One of the major barriers to compliance with eVTP identified in this study was not patient related, but rather doctor mediated. For the 80 eligible patients who consented to undertake this study, only 65 were prescribed LMWH on their discharge script. The reasons included changeover of junior staff unaware of eVTP prescription and/or LMWH not charted on discharge script despite patient being flagged as a study participant. This is partly a reflection of guideline implementation in Australia which is a bottom up educational approach - delivered by individuals, units or institutions rather than a top down governance approach such as occurs in the United Kingdom (NHS). 
A limitation of the study is the 20 patients who refused to consent to eVTP. This may have created a motivational bias in the selected group, as the remaining patients were those more likely to comply with the injection regime, and follow up. No patients in the non-participant cohort had a clinical VTE. We did not enrol patients in a post-operative surveillance for non-clinical VTE - such as doppler USS or venogram - and left treating clinicians to investigate any possible VTE symptoms. The primary aim of the study was safety and efficacy of eVTP and was not powered to investigate any effect on VTE.

\section{CONCLUSION}

This study demonstrates that provision of eVTP in patients undergoing major hepato-biliary and upper GI surgery is safe and well tolerated, with minimal morbidity, good compliance and efficacy. Furthermore, the major roadblock to compliance is not patient but rather doctor mediated. If a patient is identified, educated, and discharged with the equipment to undergo eVTP, the majority will complete the course safely, with high level of tolerance and compliance.

\section{CONFLICTS OF INTEREST}

There are no conflicts of interest with the authors of the study. No grants or financial assistance was received 


\section{BIBLIOGRAPHY}

1. Horsted F, West J, Grainge MJ. Risk of venous thromboembolism in patients with cancer: a systematic review and meta-analysis. PLoS Med.2012.9

2. Samama MM, Cohen AT, Darmon JY, Desjardins L, Eldor A. A comparison of enoxaparin with placebo for the prevention of venous thromboembolism in acutely ill medical patients.

Prophylaxis in Medical Patients with Enoxaparin Study Group. N Eng/ J Med.1999.341:793800

3. Bergqvist D, Agnelli G, Cohen A, Eldor A. Duration of Prophylaxis against Venous Thromboembolism with Enoxaparin after Surgery for Cancer. N Engl J Med.2002.346:975980

This article is protected by copyright. All rights reserved. 
4. Berg H, Jensen R, Kirchhoff-Jensen R, Rasmussen S, Wille-Jørgensen P. Low molecular weight heparin (Innohep) as thromboprophylaxis in outpatients with a plaster cast: A venographic controlled study.Thrombosis research.2002.105:477-480

5. Rasmussen MS, Jorgensen LN, Wille-Jorgensen P. Prolonged thromboprophylaxis with low molecular weight heparin for abdominal or pelvic surgery. Cochrane Database of Systematic Reviews.2001.1:CD004318

6. National Institute for Clinical Excellence - Acute and Chronic Conditions, "Venous thromboembolism: reducing the risk of venous thromboembolism (deep vein thrombosis and pulmonary embolism) in patients admitted to hospital”. 2010.

7. Geerts WH, Bergqvist D, Pineo GF. Prevention of venous thromboembolism: American college of chest physicians evidence-based clinical practice guidelines (8th edition) Chest. 2008.133:381S-453S.

8. Clinical Practice Guideline for the Prevention of Venous Thromboembolism (Deep Vein Thrombosis and Pulmonary Embolism) in Patients Admitted to Australian Hospitals (2009) National Health and Medical Research Council

9. Sanofi Clexane Educational material http://www.guildlink.com.au/gc/ws/sw/cmi.cfm?product=swcclexa10117

10. Anderson FA Jr, Zayaruzny M, Heit JA, Fidan D, Cohen AT. Estimated annual numbers of US acute-care hospital patients at risk for venous thromboembolism. Am J Hematol. 2008. Sep;82:777-82.

11. Sweetland S, Green J, Liu B, Berrington de Gonzalez A, Canonico M, Reeves G, Sweetland, V. Duration and magnitude of the postoperative risk of venous thromboembolism in middle aged women: prospective cohort study. BMJ.2009.339:b4583 
12. Tzeng C, Katz M, Fleming J, Pisters P. Risk of venous thromboembolism outweighs posthepatectomy bleeding complications: analysis of 5651 National Surgical Quality Improvement Program patients. HPB.2012.1:506-513

13. Prandoni P, Falanga A, Piccioli A. Cancer and venous thromboembolism. Lancet Oncol. 2005.6:401-10.

14. Kourlaba G, Relakis J, Mylonas C, Kapaki V, Kontodimas S, Holm MV, Maniadakis N. The humanistic and economic burden of venous thromboembolism in cancer patients: a systematic review. Blood Coagul Fibrinolysis.2015.26:13-31

15. Auer RA, Scheer AS, McSparron JI, Schulman AR, Tuorto S. Postoperative venous thromboembolism predicts survival in cancer patients. Ann Surg.2012.255 963-70

16. Dentali F, Ageno W, Pierfranceschi MG, Imberti D, Malato A, Nitti C, Salvi A. Prognostic relevance of an asymptomatic venous thromboembolism in patients with cancer. J Thromb Haemost.2011.9:1081-3

17. Kakkar AK, Haas S, Wolf $\mathrm{H}$. Evaluation of perioperative fatal pulmonary embolism and death in cancer surgical patients: the MC-4 cancer substudy. Thromb Haemost. 2015. 94:867-871.

18. Merkow RP, Bilimoria KY, McCarter MD, Cohen ME, Barnett CC, Raval MV. Post-discharge venous thromboembolism after cancer surgery: extending the case for extended prophylaxis. Ann Surg.2011.254:131-7.

19. Rasmussen $M$, Jorgensen $L$, Wille-Jorgensen $P$ Prolonged prophylaxis with dalteparin to prevent late thromboembolic complications in patients undergoing major abdominal surgery: A multicentre randomised open-label study. J Thromb Haemost.2006.4:2384-2390 
20. Vedovati M, Becattini C, Rondelli F. A Randomised Study on 1-week versus 4-week prophylaxis for Venous Thromboembolism after laparoscopic surgery for colorectal cancer. Ann Surg.2014.259: 4:665-669

21. Merkow RP, Bilimoria KY, Sohn MW, Oh EH, Sellers MM, Paruch JL. Adherence with post discharge venous thromboembolism chemoprophylaxis recommendations after colorectal cancer surgery among elderly Medicare beneficiaries. Ann Surg.2014.260:103 -8.

22. Kalka C, Spirk D, Siebenrock KA, Metzger U, Tuor P, Sterzing D, Oehy K. Lack of extended venous thromboembolism prophylaxis in high-risk patients undergoing major orthopaedic or major cancer surgery: Electronic Assessment of VTE Prophylaxis in High-Risk Surgical Patients at Discharge from Swiss Hospitals. Thromb Haemost.2009.102:56-61

23. IUA guidelines 2013 Prevention and treatment of venous thromboembolism international consensus statement. International Angiology.32:2

24. G. Rajarathinam,囚 D.G. Kannan, V. Vimalraj, A. Amudhan, S. Rajendran, D. Jyotibasu. Post pancreaticoduodenectomy haemorrhage: outcome prediction based on new ISGPS Clinical severity grading. $H P B .2008 .10: 363-370$.

25. Vázquez FJ, Bilbao MS, Saimovici J, Vaccaro C. Improving Adherence Rate of Extended Prophylaxis for Venous Thromboembolic Disease After Abdominal and Pelvic Oncologic Surgery: A Pilot Educational Study. Clin Appl Thromb Hemost. 2015.21:750 -4

26. Reddy SK, Turley RS, Barbas AS, Steel JL, Tsung A, Marsh JW, Clary BM. Post-operative pharmacologic thromboprophylaxis after major hepatectomy: does peripheral venous thromboembolism prevention outweigh bleeding risks? J Gastrointest Surg.2011. 15:160210 
27. Tzeng CW, Katz MH, Fleming JB, Pisters PW, Lee JE, Abdalla EK, Curley SA. Risk of venous thromboembolism outweighs post-hepatectomy bleeding complications: analysis of $\mathbf{5 6 5 1}$ National Surgical Quality Improvement Program patients. HPB.2012.14:506

This article is protected by copyright. All rights reserved. 
Fig. 1 Number of missed injections per study participant

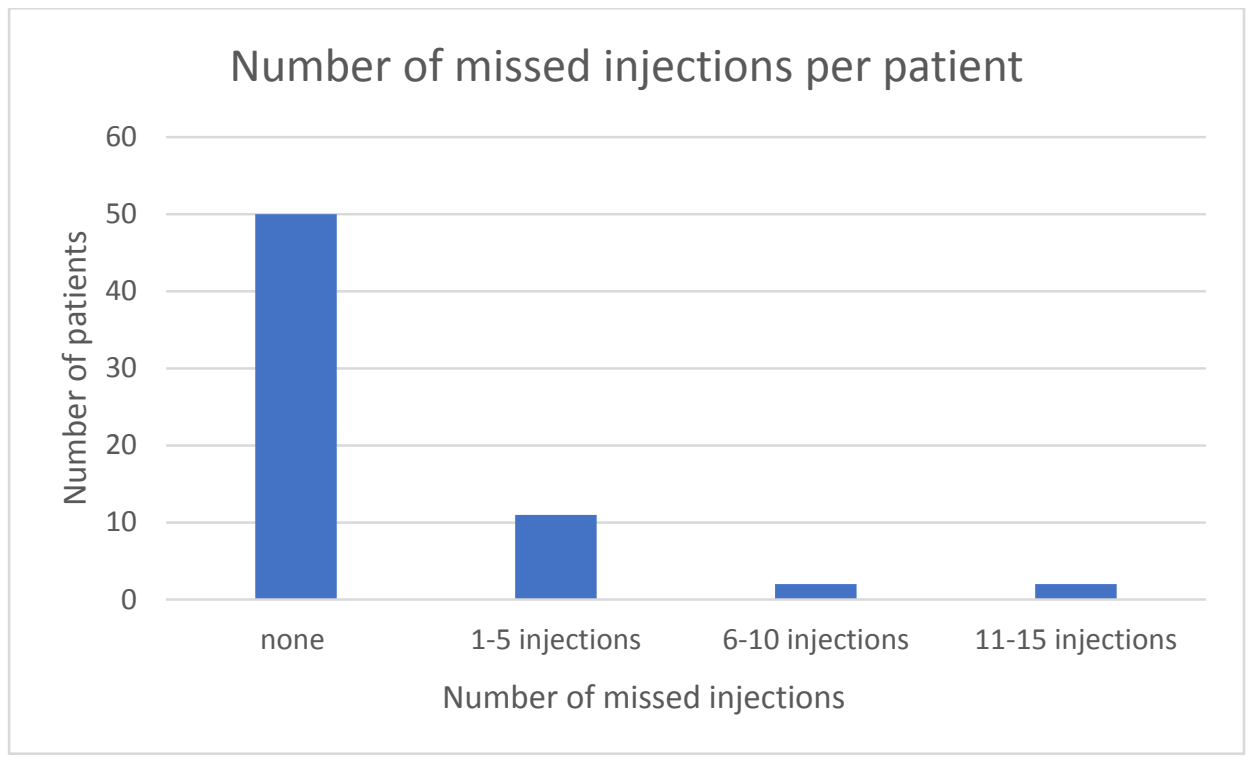

This article is protected by copyright. All rights reserved. 
Fig. 2-Complications reported by study participants

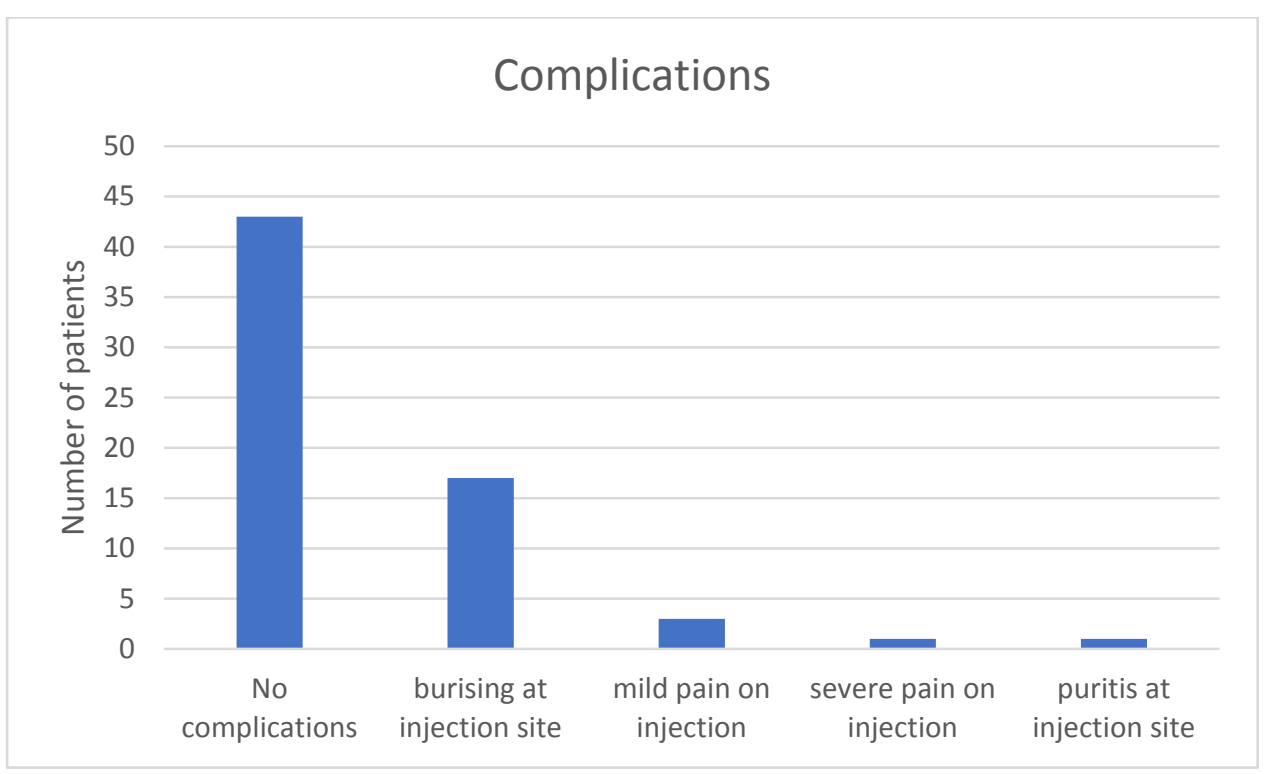

This article is protected by copyright. All rights reserved. 
Table 1 - Patent demographics

\begin{tabular}{|c|c|}
\hline \multicolumn{2}{|l|}{ Patient Demographics } \\
\hline Gender & Total (\%) \\
\hline Male : Female & $44(68 \%): 21(32 \%)$ \\
\hline Age Range (years) & Median: 62 (range 21 - 87) years \\
\hline $20-40$ & $4(6 \%)$ \\
\hline $41-60$ & $20(31 \%)$ \\
\hline $61-80$ & $39(60 \%)$ \\
\hline$>80$ & $2(3 \%)$ \\
\hline Diagnosis & \\
\hline Colorectal liver metastasis & $18(28 \%)$ \\
\hline Pancreatic Cancer/IPMN & $14(22 \%)$ \\
\hline Hepatocellular Carcinoma & $9(14 \%)$ \\
\hline
\end{tabular}

This article is protected by copyright. All rights reserved. 
Gastric Cancer

Oesophageal Cancer

Cholangiocarcinoma

Gallbladder Cancer

Neuroendocrine $\mathrm{Ca}$

Metastatic melanoma

\section{Procedure}

Liver resection

$28(43 \%)$

Pancreaticoduodenectomy or

$19(29 \%)$

distal pancreatectomy

Total/partial gastrectomy

Ivor Lewis Oesophagectomy

Extended Cholecystectomy
$1(1 \%)$

$8(12 \%)$

$9(14 \%)$

$8(12 \%)$

$4(7 \%)$

$1(1 \%)$

$1(1 \%)$

$9(14 \%)$

$1(2 \%)$

This article is protected by copyright. All rights reserved. 


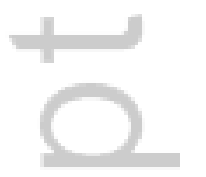

This article is protected by copyright. All rights reserved. 


\section{University Library}

\section{- M M N E R VA A gateway to Melbourne's research publications}

Minerva Access is the Institutional Repository of The University of Melbourne

Author/s:

Marley, L;Navadgi, S;Banting, S;Fox, A;Hii, M;Knowles, B

Title:

Safety, efficacy and compliance of extended thromboprophylaxis in hepatobiliary and upper gastrointestinal surgery

Date:

2019-04-01

Citation:

Marley, L., Navadgi, S., Banting, S., Fox, A., Hii, M. \& Knowles, B. (2019). Safety, efficacy and compliance of extended thromboprophylaxis in hepatobiliary and upper gastrointestinal surgery. ANZ JOURNAL OF SURGERY, 89 (4), pp.357-361. https://doi.org/10.1111/ ans. 14287.

Persistent Link:

http://hdl.handle.net/11343/284174 